\title{
Evaluation of prophylactic and therapeutic effects of sildenafil on acute radiation proctitis in rats ${ }^{1}$
}

Erkan Yavuz', Gulcin Ercan', Onur Olgac Karagulle', Busra Yaprak Bayrak", Aytac Biricik', Candas Ercetin', Berk Gokcek'", Hakan Yigitbas', Ramazan Kusaslan', Atilla Celik', Osman Bilgin Gulcicek'

'MD, Department of General Surgery, University of Health Science Bagcilar Training and Research Hospital, Istanbul, Turkey. Scientific, intellectual, conception and design of the study; analysis and interpretation of data; technical procedures; critical revision; final approval.

"MD, Department of Pathology, University of Health Science Derince Training and Research Hospital, Kocaeli, Turkey. Histopathological examinations, acquisition of data, statistical analysis.

I'MD, Department of General Surgery, University of Health Science Okmeydanı Training and Research Hospital, Istanbul, Turkey. Manuscript preparation and writing, critical revision.

\section{Abstract}

Purpose: To investigate the prophylactic and therapeutical effects of sildenafil in a model of acute radiation proctitis (ARP).

Methods: All experimental procedures of this study was examined by histopathological, immunohistochemical and transmission electron microscopic analysis.

Results: Our histopathological evaluations indicated significant increases in lesion severity, cryptic apsis, cryptitis, cryptic distortion, reactive atypia and infiltration depth of the control (proctitis) group. While the prophylaxis group and the treatment group had significantly lower scores. High-dose group showed similar results as prophylaxis group. Histopathological findings of the prophylaxis group was more significant than the treatment group. Immunoreactivities of IL-1 $\beta$, FGF-2, TNF- $\alpha$ and HIF-1 $\alpha$ increased in the control group especially in the epithelial and cryptic regions. On the contrary, sildenafil application caused significant decreases of inflammatory markers in all treatment groups, specifically better results in the prophylaxis group.

Conclusion: The sildenafil has anti-inflammatory effects on ARP, as well as protective effects against ARP and the protective effect of sildenafil surpasses its therapeutic effect histopathologically.

Key words: Sildenafil Citrate. Proctitis. Inflammation. Ultrastructure. Rats. 


\section{Introduction}

Clinical radiation to the pelvic region has been performed to treat the rectum cancer, gynecological malignities, prostate cancer and lymphoma. Acute Radiation Proctitis (ARP) is inflammation and damage to the rectum, appeared as a major clinical complication of ionizing radiation ${ }^{1,2}$. More than $75 \%$ of the patients received radiation therapy have the symptoms of ARP and only $20 \%$ of them have symptoms related to the chronic radiation proctitis (CRP) $)^{3-4}$.

The pathogenesis of radiation proctitis has not been clarified totally yet. However, it is known that firstly mucosal damage is observed due to the radiation, subsequently connective tissue is enlarged and remodeled, lastly fibrosis and ischemia are observed ${ }^{5}$. These kinds of pathological damage are varied in ARP and CRP. Cryptic apsis and cryptitis are generally observed in acute radiation proctitis. Moreover, $\mathrm{T}$ lymphocytes, macrophages and neutrophils are designated in the process $s^{5,6}$.

There are many therapeutical and protective methods against the radiation proctitis whereas none of them are gold standards. Many previous reports focus on the various methods used for treating ongoing inflammation but fail to address its pathophysiology. There is therefore the need for a better understanding of the precise mechanisms underlying radiation-induced proctitis to determine best methods of protection and treatment ${ }^{7}$.

Sildenafil, which was developed for the treatment of erectile dysfunction, inhibits cyclic guanosine monophosphatespecific phosphodiesterase-5, an enzyme that is abundantly present in the pulmonary vasculature, and thereby promotes nitric oxide-mediated vasodilatation, which in turn decreases pulmonary vascular resistance ${ }^{8,9}$. Recently several studies have reported the beneficial effects of sildenafil to treat inflammatory diseases, to alleviate the endothelial cell dysfunction that can occur under conditions of ischemia reperfusion injury ${ }^{10-12}$, chronic heart failure ${ }^{13}$, and coronary artery disease ${ }^{14,15}$. However, the mechanism of how sildenafil affect inflammatory processes in ARP or CRP is not known yet.

In this study, our purpose is to investigate the prophylactic and therapeutical effects of sildenafil in a model of ARP by histopathological, immunohistochemical and transmission electron microscopical analysis.

\section{- Methods}

All experimental procedures of this study was approved by the Animal Care and Use Committee of The University of Health Sciences Bagcilar Training and Research Hospital approved (Protocol No:2015-17).

Forty female Sprague- Dawley rats (250 \pm 30 g, with ages 4-8 weeks), supplied by the Bagcilar Training and Research Hospital Animal Center (BADABEM), Istanbul, Turkey, were kept under the laboratory conditions of the same center, housed in a controlled room with 12 -hour lighte-dark cycles at $22^{\circ} \mathrm{C}$, and fed with standard pellet chow including $21 \%$ protein and daily fresh water. All rats were captured in separate cages including 8 rats in each one and were divided into five random groups ( $n=8)$ as;

Group 1.; Sham group received equal amount of isotonic solution,group 2; Control (Radiation) group received Radiation (RT) + equal amount of isotonic solution,group 3; Prophylaxis group received $10 \mathrm{mg} / \mathrm{kg} /$ day Sildenafil for 7 days,group 4; Treatment group received first RT and then $10 \mathrm{mg} / \mathrm{kg} /$ day Sildenafil for 15 days,group 5; High dose group received first RT and then $50 \mathrm{mg} / \mathrm{kg} / \mathrm{day}$ Sildenafil for 15 days 


\section{Establishment of radiation proctitis}

All rats of RT applied groups, except sham group, were fixed on an acrylic plate on back position by strapping the tails and legs under anesthesia by $5 \mathrm{mg} / \mathrm{kg}$ xylazine (Rompun-Bayer-Germany) and $30 \mathrm{mg} / \mathrm{kg}$ ketamine (Ketalar-Pfizer-Turkey) (Figure 1). All parts of the body and extremities were excluded from the radiation area except the target lower pelvic region in $3 \times 4 \mathrm{~cm}$ dimension including 2 $\mathrm{cm}$ long rectum. The dimensions of radiation area (Elekta, Model Precise Treatment System, $6 \mathrm{mev}$ electron energy, 0.5 bolus material) were $20 \times 20 \mathrm{~cm}^{2}$ and a single fraction of $2500 \mathrm{cGy}$ was given ${ }^{16}$.
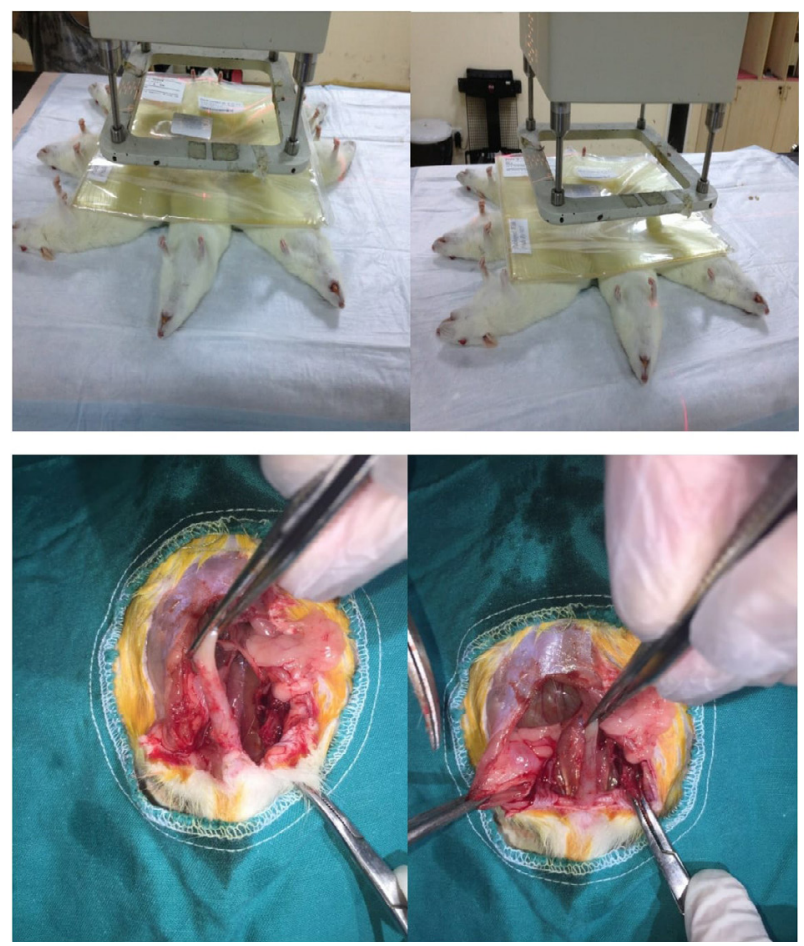

Figure 1 - Application of radiation (above) and dissection of rectums (below) after the sacrification of rats.

A single $10 \mathrm{mg} / \mathrm{kg} /$ day dose of Sildenafil (INDEA $165459 / N$ ) was injected daily by oral gavage to Group 3 for 7 days before radiation. Group 4 was only injected for 15 days after radiation. Group 1 was injected by daily single dose of isotonic solution at the same volume by oral gavage for 15 days without performing radiation. Group 2 was injected by daily single dose of isotonic solution at same volume by oral gavage for 15 days after radiation. None of the rats died during the experiment.

Laparotomy was performed on every animals at $15^{\text {th }}$ days of radiotherapy under ketamine anesthesia $(10 \mathrm{mg} / \mathrm{kg}$ xyilazine and $60 \mathrm{mg} / \mathrm{kg}$ ketamine) (Figure 1); the rats were sacrificied by intracardiac puncture.

Rectums were dissected and washed with isotonic solution for histopathological, immunohistochemical and ultrastructural evaluations. Under observation of a pathologist, the tissues were cut into 3 equal horizontal pieces and put into relevant fixatives ${ }^{17}$.

\section{Histopathological evaluation}

All relevant pieces of rectal segments were cut into $1 \mathrm{~cm}^{3}$ size, fixed by $4 \%$ neutral formalin, applied routine procedure for tissue preparation and embedded into the paraffin blocks. $5 \mu \mathrm{m}$ paraffin sections were stained by hematoxylin and eosin and evaluated by the pathologist as blind for twice under a light microscope and photographed (Nikon Eclipse E600).

Lamina propria (inflammation), invasion of leucocytes through the cryptic epithelium (cryptitis), deterioration of crypts (cryptic distortion), regenerative / restorative atypia of epithelial cells (reactive atypia) and inflammatory infiltration were investigated. Severity of the lesion was evaluated as scores between 0-3; 0: None, 1: mild lesion, 2: moderate lesion and 3: severe lesion ${ }^{16}$.

Cryptit apsis was noted as positive or negative for each slide. Infiltration depth was 
measured by an image analysis system of a video attached microscope (Zeiss Axioplan 2).

\section{Immunohistochemical analysis}

All relevant pieces of rectal segments were fixed by $4 \%$ neutral formalin, applied routine procedure for tissue preparation and embedded into the paraffin blocks. $5 \mu \mathrm{m}$-thick sections were stained immunohistochemically by using Streptavidin-Biotin-Peroxidase method with monoclonal and polyclonal antibodies tagged to indicate cell and tissue antigens, according to previously described method $^{17}$. Primary antibodies against inflammatory markers for tumor necrosis factor $\alpha($ TNF- $\alpha)$, hypoxia-inducible factor $1 \alpha$ (HIF- $1 \alpha)$, interleukin $1 \beta$ (IL-1 $\beta$ ) and fibroblast growth factor 2 (FGF-2) and angiogenesis marker of vascular endothelial growth factor (VEGF) were used. Positively stained cells with relevant antigens were analyzed semi-quantitatively in terms of staining intensity (modified H-SCORE analysis) ${ }^{17}$. Thereby rectal localization of these proteins and variance of the staining intensity and regional differences were determined.

\section{Transmission electron microscopic analysis}

Rectal segments in size of $1 \mathrm{~mm}^{3}$ were fixed by $2.5 \%$ glutaraldehyde and prepared for ultrastructural analysis as described before ${ }^{18}$. Sections were evaluated under a transmission electron microscope (Jeol Jem 1011). The images were transferred to Soft Imaging System Analysis programme by Megaview III digital camera and pictures were taken.

\section{Statistical analysis}

Semi-quantitative analysis of cytokines stained in tissue of all rats was performed by modified H-SCORE, given values between
0-300 for five different regions of each slide. Statistical analysis was performed by GraphPad Instat ver. 3.06 (GraphPad Inc, CA, USA) program. Mean values of continuous variables are compared by one way ANOVA and variations between groups were compared by Tukey-Kramer Multiple Comparison Test. Categorical variables were evaluated by Chisquare test. $p<0.05, p<0.01$ and $p<0.001$ were accepted as statistically significant for different values of the groups.

\section{- Results}

\section{Histopathological examination}

Light micrographs of rectal tissues stained with H\&E were given in Figure 2. As a result of light microscopic evaluations, histological structure of the mucosa and submucosa, cryptic glands and other epithelial components were observed to be preserved in the sham group, as expected. However, the micrographs of the control group presented a damaged mucosal structure, high levels of epithelial degenerations with decreased amount of cryptic glands and exacerbated surface. Histopathological evaluations disclosed that the thickness of mucosa increased locally due to cryptitis and cryptic apsis; leucocyte infiltration and fibrosis were observed in the submucosa. The prophylaxis and treatment groups established the normal structures of the mucosal and submucosal components, similar appearing with the sham group. The surface epithelium, cryptic glands and lamina propria were approximately wellpreserved. However, these components could not show improvements enough in the highdose group, compared to the prophylaxis and treatment groups (Figure 2).

Figure 2 Light micrographs of rectum samples from experimental rat model of 
radiation proctitis, $H \& E, x 100$. a: Sham group, b: Control (radiation) group, c: Prophylaxis group, d: Treatment group, e: High-dose. E:
Surface epithelium, C: Cryptic glands, S: Stroma with lamina propria, Su: Submucosa, L: Lumen of rectum.

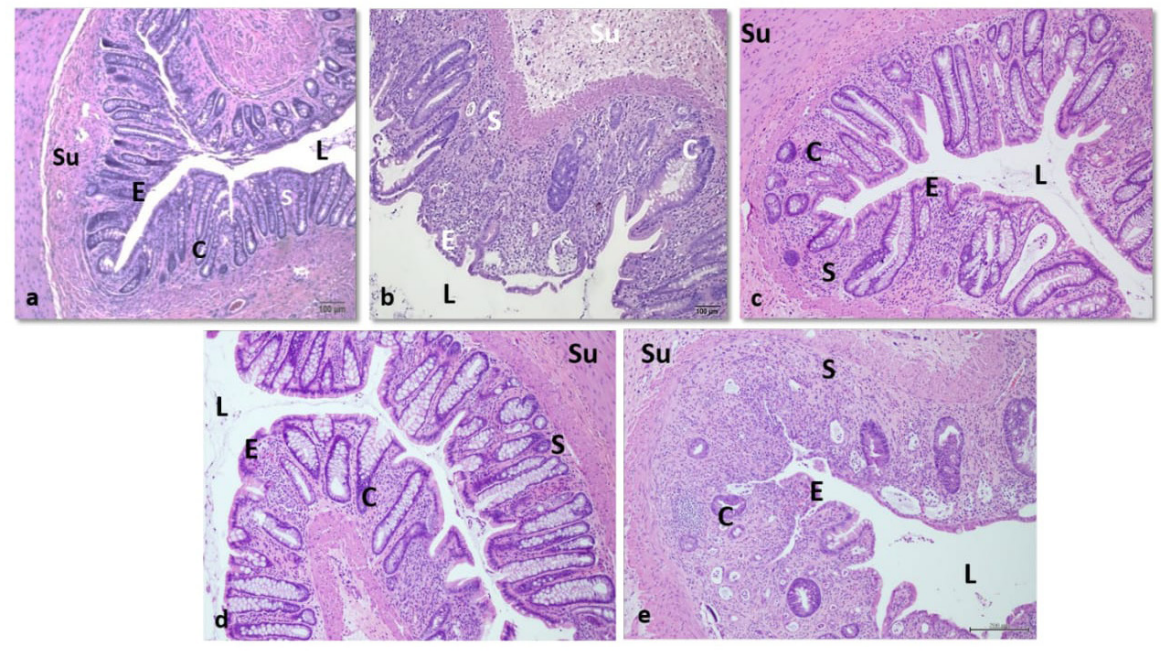

Figure 2 - Light micrographs of rectum samples from experimental rat model of radiation proctitis, H\&E, x100. a: Sham group. b: Control (radiation) group. c: Prophylaxis group. d: Treatment group. e: High-dose. (E: Surface epithelium, C: Cryptic glands, S: Stroma with lamina propria, Su: Submucosa, L: Lumen of rectum).

Inflammation, lesion severity, cryptic apsis, cryptitis, cryptic distortion in lamina propria, reactive atypia of epithelial cells and inflammatory infiltration depth were evaluated in H\&E stained tissues and lesion severities were graded in 0-3 points (Table 1 ). Lesion severity of sham group was found as 0 (no lesion) while its mean was estimated as 2.38 (moderate-severe lesion) in the control and treatment groups; 2 (moderate) for prophylaxis group and 2.86 (moderate-severe lesion) for high-dose group. So it was observed to significantly decrease only in the prophylaxis group compared to the control group ( $p<0.05)$.

There were statistically significant increases in cryptic apsis, cryptitis and cryptic distortion in the control group, compared to the sham group $(p<0.001)$ while significant decreases were revealed in cryptic apsis and distortion of the treatment group $(p<0.001)$ and in cryptitis and cryptic distortion of prophylaxis and high-dose groups ( $p<0.01)$. Reactive atypia could not be ameliorated in any of sildenafil applied groups (Table 1 ).

A significant increase was detected for infiltration depth in mucosa of the control group measured by light microscopy, compared to the other groups $(p<0.01)$. There was not any difference between sham, treatment and prophylaxis groups (Table 1) but there was a significant difference between sham and high-dose group $(p<0.001)$. Thus, treatment with sildenafil significantly decreased the inflammatory infiltration depth, compared to the radiation group. 
Table 1 - Histopathological findings of five experimental groups in the model of acute radiation proctitis.

\begin{tabular}{lllllll}
\hline GROUPS & $\begin{array}{l}\text { Lesion Sever- } \\
\text { ity (Mean } \pm \text { SD) }\end{array}$ & $\begin{array}{l}\text { Cryptic } \\
\text { Apsis } \mathbf{n}(\%)\end{array}$ & $\begin{array}{l}\text { Cryptitis } \\
\mathbf{n}(\%)\end{array}$ & $\begin{array}{l}\text { Cryptic } \\
\text { distortion } \\
\mathbf{n}(\%)\end{array}$ & $\begin{array}{l}\text { Reactive } \\
\text { atypia } \\
\mathbf{n}(\%)\end{array}$ & $\begin{array}{l}\text { Infiltration } \\
\text { Depth }(\boldsymbol{\mu m}) \\
\text { (Mean } \pm S D)\end{array}$ \\
\hline Sham & $0^{\mathrm{a}}$ & $0(0)^{\mathrm{a}}$ & $0(0)^{\mathrm{a}}$ & $0(0)^{\mathrm{a}}$ & $0(0)^{\mathrm{a}}$ & $102.78 \pm 17.1$ \\
Control & $2.38 \pm 0.5$ & $8(100)^{\mathrm{c}}$ & $8(100)$ & $7(87,5)^{\mathrm{c}}$ & $3(37,5)$ & $509.63 \pm 158.9^{\mathrm{c}}$ \\
Treatment & $2.38 \pm 0.5$ & $5(62.5)^{\mathrm{d}}$ & $8(100)$ & $4(50)^{\mathrm{d}}$ & $3(37,5)$ & $224.71 \pm 25.9$ \\
Prophylaxis & $2.0 \pm 0.8^{\mathrm{b}}$ & $7(87.5)$ & $7(87.5)^{\mathrm{e}}$ & $5(62.5)^{\mathrm{b}}$ & $4(50)^{\mathrm{e}}$ & $212.27 \pm 55.7$ \\
High-dose & $2.86 \pm 0.4$ & $7(87.5)$ & $7(87.5)^{\mathrm{e}}$ & $6(75)^{\mathrm{e}}$ & $6(75)^{\mathrm{e}}$ & $278.15 \pm 46.4^{\mathrm{a}}$ \\
\hline
\end{tabular}

a $p<0.001$ Sham group vs. other groups ${ }^{\mathrm{b}} p<0.05$ vs. high-dose group

${ }^{c} p<0.01$ Control group vs. other groups

${ }^{\mathrm{d}} p<0.001$ vs. prophylaxis and high-dose groups

${ }^{e} p<0.01$ vs. control and treatment groups

SD: Standard deviation

Immunohistochemical analysis

H-SCORE analysis of immunoreactivities for inflammation markers of IL-1 $\beta$, FGF-2, TNF- $\alpha$, HIF- $1 \alpha$, and angiogenesis marker of VEGF were given in Table 2. Immunoreactivities on rectal tissues were evaluated for three regions: Epithelium, crypts and stroma.

Immunoreactivity of the first cytokine, IL-1 $\beta$, showed a significant increase in epithelium, crypts and stroma of the control group compared with other groups while the treatment, prophylaxis and high-dose groups indicated significant decreases $(p<0.05)$ (Table $2)$. These decreases in immunoreactivities were also detected for FGF-2 cytokine in the epithelial and cryptic regions of the treatment, prophylaxis and high-dose groups compared with the control group $(<0.01)$, except the stromal regions of three experimental groups showed no difference for FGF-2 immunoreactivity (Table 2).

Immunoreactivity of the third cytokine,
TNF- $\alpha$ increased significantly in the epithelium and crypts of the control group, compared to the other groups $(p<0.01)$ and decreased significantly in the treatment, prophylaxis and high dose groups (Table 2). Stroma had not such significant differences (Table 2), even for the control group.

There was significant increases in immunoreactivity of HIF- $1 \alpha$ in epithelium, crypts and stromal regions of the control group, in regard to the other groups $(p<0.001)$ and significant decreases in the treatment, prophylaxis and high dose groups $(p<0.001)$ (Table 2).

Comparing the number of vessels stained for angiogenesis marker, VEGF in the stroma and submucosa, the control group showed significant increase $(p<0.01)$ and other groups had significant decreases (Table 2). In other words, the sham, treatment, prophylaxis and high-dose groups had no significant differences for VEGF immunoreactivity (Table 2). 
Table 2 - Immunohistochemical findings for reactivity of inflammatory marker on epithelial, cryptic and stromal regions of the rectum sections of five experimental groups.

\begin{tabular}{|c|c|c|c|c|c|}
\hline Mean $\pm S D$ & IL-1 $\beta$ & FGF-2 & TNF- $\alpha$ & HIF-1 $\alpha$ & VEGF \\
\hline \multicolumn{6}{|l|}{ EPITHELIUM } \\
\hline Sham & 0 & $152.5 \pm 43.7$ & $81.25 \pm 15.3$ & $137.5 \pm 44.3$ & $181.25 \pm 39.8$ \\
\hline Control & $62.5 \pm 19.45^{a}$ & $268.75 \pm 59.4^{b}$ & $160.0 \pm 39.3^{b}$ & $275.0 \pm 46.3^{\mathrm{e}}$ & $203.75 \pm 45.5$ \\
\hline Treatment & 0 & $275.0 \pm 46.3^{b}$ & $168.75 \pm 53.0^{b}$ & $237.5 \pm 58.2^{f}$ & $175.0 \pm 50.1$ \\
\hline Prophylaxis & 0 & $108.75 \pm 27.2^{c, d}$ & $62.5 \pm 14.4^{\mathrm{c}, \mathrm{d}}$ & $108.75 \pm 28.6^{c, d}$ & $77.5 \pm 19.1^{c}$ \\
\hline High-dose & $3.75 \pm 1.23$ & $164.29 \pm 55.6^{c, d}$ & $97.14 \pm 19.8^{c, d}$ & $185.71 \pm 47.6^{c}$ & $192.3 \pm 28.5$ \\
\hline \multicolumn{6}{|l|}{ CRYPTS } \\
\hline Sham & 0 & $32.50 \pm 3.2$ & $18.75 \pm 5.9$ & 0 & $25.0 \pm 6.7$ \\
\hline Control & $27.5 \pm 5.3^{\mathrm{a}}$ & $200.0 \pm 80.2^{\mathrm{a}}$ & $76.25 \pm 10.9^{a}$ & $168.75 \pm 16.3^{g}$ & $131.25 \pm 20.4^{\dagger}$ \\
\hline Treatment & 0 & $100.0 \pm 35.5$ & $43.75 \pm 7.2$ & $12.50 \pm 5.4$ & $81.25 \pm 13.6^{f}$ \\
\hline Prophylaxis & 0 & $56.25 \pm 16.3$ & $25.0 \pm 7.2$ & $2.50 \pm 1.0$ & $37.5 \pm 5.5$ \\
\hline High-dose & 0 & $65.71 \pm 23.4$ & $17.14 \pm 3.6$ & $2.86 \pm 1.0$ & $45.6 \pm 13.4$ \\
\hline \multicolumn{6}{|l|}{ STROMA } \\
\hline Sham & 0 & $46.25 \pm 3.4$ & $275.0 \pm 37.8$ & 0 & $8.38 \pm 3.1$ \\
\hline Control & $96.25 \pm 7.3^{a}$ & $212.5 \pm 79.1^{f}$ & $256.25 \pm 62.3$ & $125.0 \pm 45.5^{g}$ & $43.13 \pm 6.5^{a}$ \\
\hline Treatment & $12.5 \pm 3.1$ & $181.25 \pm 75.3^{f}$ & $243.75 \pm 82.1$ & $36.25 \pm 3.8$ & $15.5 \pm 4.7$ \\
\hline Prophylaxis & $25.0 \pm 7.8$ & $162.5 \pm 15.7^{f}$ & $225.0 \pm 70.7$ & $12.5 \pm 3.1$ & $13.38 \pm 5.4$ \\
\hline High-dose & $7.14 \pm 1.8$ & $164.29 \pm 78.8^{f}$ & $207.14 \pm 81.8$ & $28.57 \pm 6.7$ & $16.4 \pm 2.8$ \\
\hline
\end{tabular}

a $p<0.01$ vs. other groups

${ }^{\mathrm{b}} p<0.01$ vs. sham group

${ }^{c} p<0.01$ vs. control group

${ }^{\mathrm{d}} p<0.001$ vs. treatment group

${ }^{e} p<0.001$ vs. sham group

${ }^{f} p<0.05$ vs. sham group

${ }^{\mathrm{g}} p<0.001$ vs. other groups

\section{Electron microscopic analysis}

Electron microscopical results were parallel to the light microscopy as there were histopathogical changes in the control group related to acute radiation (Figure $3 \mathrm{~b} 1$ and b2). Decreased number of microvilli on the epithelium and diminished length and also apical vacuolization were remarkable on the epithelium (Figure 3b1). With atrophy and distortion on the glands, the glandular epithelium was diminished and corroded, compared to the sham group (Figure 3b1); migrated nuclei of the epithelium to the lumen side and dilatation of intercellular spaces were observed (Figure 3b2). The number of Goblet cells decreased, mucus secretion diminished and epithelial cells shrank and there were a few damaged cryptic stem cells. On some regions, microvilli were totally deleted, nuclei of the epithelium were enlarged, chromatin modelling differed, and even some gained apoptotic appearance.

On the rectum surface epithelium of the prophylaxis group, microvilli projecting through lumen at typical ultrastructure acquired their 
normal number but not the height (Figure 3c1). A large number of tight junctions also protected integrity of the epithelium. The basement membrane protected its continuity and homogeneity more or less and the intercellular area had normal digitations. Normal number but irregular distribution of the fibers was remarkable at subjacent lamina propria, compared to the sham group (Figure 3c2).

On the rectum surface epithelium of the treatment group, microvilli (white arrow) projecting through lumen at typical ultrastructure acquired their normal number and height, better than the prophylaxis group (Figure 3d1). Intercellular borders protected their distance and a large number of tight junctions protected the integrity of the epithelium. The basement membrane of the cryptic epithelium did not lose its continuity and homogeneity; but abnormal digitations were observed in the intercellular spaces.
Ultrastructure of mitochondrial (M) crista at the suprabasal locations was observed to be impaired (Figure 3d2).

In the high-dose group, the epithelium of rectum was in normal thickness, number and height, as in other treated groups; regular Goblet cells were also observed in normal ultrastructure (Figure 3e1). Intercellular spaces were observed in normal distance and number and height of microvilli projecting to the lumen were preserved with their normal structure, compared with the sham group (Figure 3e1). Many tight junctions protected the integrity of the epithelium. Unlike the control group, high-dose group preserved the continuity and homogeneity of the basement membrane and had normal digitations in the intercellular spaces; however, the treatment group had abnormal digitations. The lamina propria was remarkable to have a little increase in the extracellular matrix (Figure 3e2).
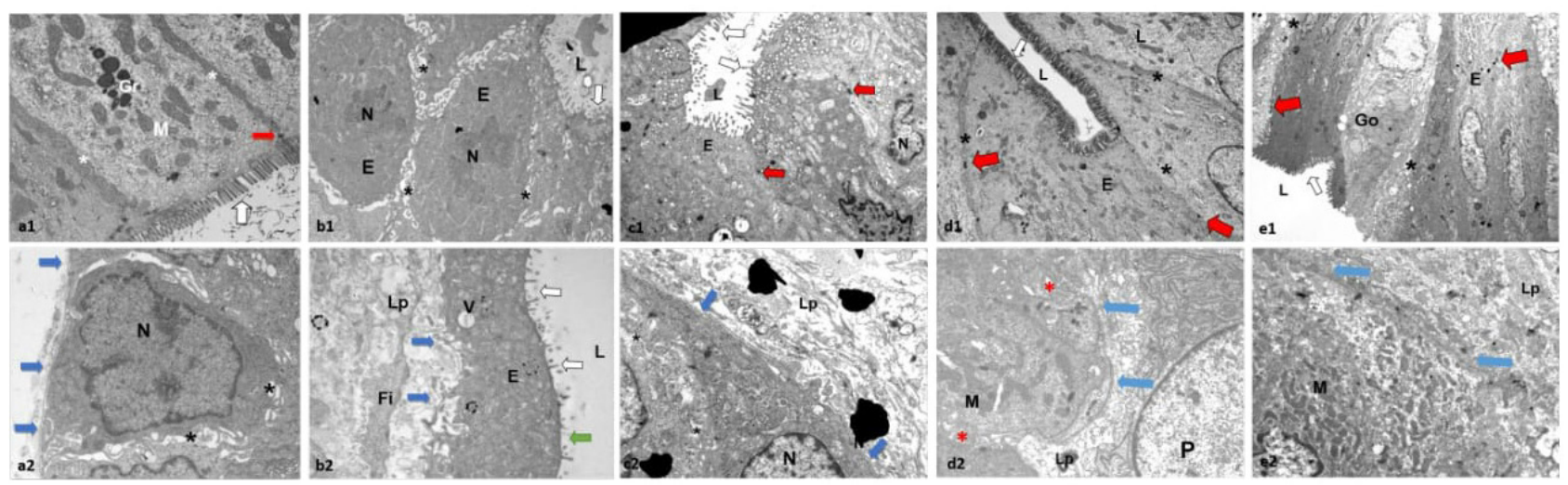

Figure 3 - Electron micrographs of rectum sections from experimental rat model of radiation proctitis. a: Sham group; a1: x12000, a2: x10000. b: Control group; b1: x7500, b2: x7500. c: Prophylaxis group; c1: x7500, c2: x12000. d: Treatment group; d1: x6000, d2: x15000. e: High-dose group; e1: x4000, x12000. (L: Lumen, White arrow: Microvilli of rectum surface epithelium, asterisks: epithelial digitations, red arrows: tight junctions, M: mitochondria, Gr: intracytoplasmic granules, N: Cryptic epithelium, blue arrows: basement membrane, E: surface epithelium, V: vacuoles, green arrows: locally nude membrane, Fi: fibrin augmentation, Lp: lamina propria, P: plasma cells, Go: Goblet cell). 


\section{- Discussion}

Preventing ARP, an inducible inflammation, has paramount importance since ARP gives rise to many difficulties in the radiation therapy. Decreasing the radiation dose or excluding the rectum from radiation area are judicious and alleviating procedures which are advised in radiation therapy, but these are not enough to ameliorate manifestations of the patients totally. Some agents such as rectal or oral misoprostol, rectal sucralfate and intravenous amifostine can be used ${ }^{19}$. However, there has not been any proven method in the literature yet, showing protective or preventive effects in ARP.

A part of the ARP can be ameliorated by supportive anti-inflammatory therapies ${ }^{19}$. Using sildenafil would be an effective approach to prevent this pathological situation whose treatment has such drawbacks ${ }^{19-23}$. Sildenafil is a selective and potent inhibitor of cyclic guanosine monophosphate (cGMP)-specific phosphodiesterase (PDE)-5, which catalyzes the hydrolysis of cGMP and has a relaxant effect on the smooth muscle cells of the arterioles supplying the human corpus cavernosum $^{24}$. The data of a recent study have shown that sildenafil, acting via a nitric oxide (NO)-dependent mechanism, prevented indomethacin-induced gastropathy, possibly through a reduction of leukocyte adhesion and maintenance of gastric blood flow ${ }^{25}$. Two studies by Iseri and Yildirim et al. ${ }^{26,27}$ demonstrated the beneficial anti-inflammatory actions of sildenafil on acetic acid-induced acute colitis and bleomycin-induced lung fibrosismodels in rats via prevention of lipid peroxidation, oxidant generation, cytokine production and neutrophil accumulation. As observed by Wang et al. $^{28}$ and Jeong et al. ${ }^{29}$ sildenafil attenuated airway inflammation and mucus production in the rat model, through the NO/cyclic guanosine $3^{\prime}, 5^{\prime}$-monophosphate pathway and significantly prevented renal damage by ameliorating oxidative and inflammatory injuries in diabetic rats.

Given the importance of inflammation involved in the ARP, there is a need for a treatment and protection modality against ARP that can block the inflammatory processes, and advances in the understanding of the pathogenesis of ARP have created a trend of novelbiological therapies thatspecificallyinhibit the molecules involved in the inflammatory cascade $^{30}$. Considering the mode of action of sildenafil in inflammation, we investigated the possible protective and therapeutic effects of sildenafil on the histology and ultrastructure of rectal tissue and inflammatory and angiogenic status induced by radiation in a rat model of ARP. In this study, markers of IL-1 $\beta$, TNF- $\alpha$ and HIF1 $\alpha$ cytokines were investigated to show the inflammation; FGF2 was used as a marker to determine the fibrosis in the rectal tissue, and VEGF marker was used to present the angiogenesis.

The cytokine IL-1 $\beta$, initiator of prostaglandin synthesis in polymorphonuclear leucocytes and connective tissue cells, has coeffects with TNF. In addition, it activates the vascular endothelial cells ${ }^{23}$. TNF has an effect of oxidative damage on the endothelial cells and increases the number of adhesion molecules; also induces angiogenesis and arranges hematopoiesis. Moreover, angiogenesis and endothelial cell proliferation can also be induced by FGF or VEGF ${ }^{23}$.

HIF-1 detects the changes in oxygen concentrations at the cell level and as a response, induces formation of new vessels and organizes many metabolisms such as anaerobic glycolysis ${ }^{23}$.

VEGF overexpression has been shown to be associated with neovascularization in neoplastic tumors, and both chemotherapy and 
radiotherapy have been found to increase VEGF expression within tumors ${ }^{24}$. It is commonly known that radiation involves the formation of reactive oxygen species and reactive nitric oxide species, which induce stress responses and inflammation, as well as the release of cytokines, growth factors and chemokines. The production of free radicals following exposure to ionizing irradiation causes DNA damage ${ }^{25}$.

In our study, immunoreactivities of IL-1 $\beta$, FGF-2, TNF- $\alpha$ and HIF-1 $\alpha$ increased in the control group of ARP especially in the epithelial and cryptic regions, compared to the treatment groups while VEGF reactivity of the control group also increased in stromal vessels, compared to other groups. On the contrary, sildenafil application caused significant decreases of inflammatory markers in all treatment groups, specifically better results in the prophylaxis group. Thus, it shows that sildenafil has anti-inflammatory effects on ARP, as well as protective effects against ARP.

Our histopathological evaluations indicated significant increases in lesion severity, cryptic apsis, cryptitis, cryptic distortion, reactive atypia and infiltration depth of the control (proctitis) group. On the other hand, treated groups showed different results in histopathological findings. While the prophylaxis group had significantly lower scores for lesion severity, cryptitis, cryptic distortion and infiltration depth, the treatment group had lower scores for cryptic apsis, distortion and infiltration depth. High-dose group showed similar results as prophylaxis group, except the infiltration depth was not significantly different from the control group. Generally considering these light microscopic evaluations, histopathological findings of the prophylaxis group was more significant than the treatment group. In other words, the protective effect of sildenafil surpasses its therapeutic effect histopathologically.
Many agents like sildenafil that can be effective on the damage of acute radiation has been investigated in several studies. In a study by Ito et $\mathrm{al}^{33}$ searching the effect of $\mathrm{C}$ vitamin against lethal intestinal damage induced by the radiation, pre-radiation and post-radiation application of $C$ vitamin caused decrease in cytokine levels (TNF and IL-6) in the intestine of rats. Our immunohistochemical analysis demonstrated that sildenafil application resulted in decreased levels of IL-1 $\beta$ and TNF markers, compared to the proctitis group.

Although there is an unfortunate lack of literature about ultrastructure of the rectum in ARP, in a report by Haboubi et al. ${ }^{34}$, rectal biopsies of six patients with ARP have been evaluated by electron microscopy. As a result, epithelial changes, fibrosis, variations in the lamina propria and cryptic distortion were detected ultrastructurally. These findings are parallel to our electron microscopic results of the experimental rat model of ARP. Moreover, this is the first study that evaluates and indicates ultrastructural changes in a therapeutical and protective model of sildenafil against ARP.

There are also other agents that have been used as treatment or protection against ARP. In an experimental ARP model by Sezer et al. ${ }^{16}$, histopathological data have been evaluated and hesperidine and diosmin have been proven to be effective. In addition, Doi et $a l .{ }^{21}$ have investigated the effects of polaprezinc in an experimental report and found as to be histopathological and endoscopical effective on ARP.

In parallel to aforementioned light microscopic findings, our electron microscopic analysis showed histopathological changes in the control group due to the acute radiation. Both treatment and prophylaxis groups demonstrated improvements in ultrastructure of the mucosa and submucosa and most of the damage depending on ARP was ameliorated. 
Even the high-dose group presented alleviations except the densified extracellular matrix in the lamina propria. To sum up, electron microscopic analysis of the prophylaxis and treatment groups indicated the therapeutical and protective effects of sildenafil on ARP and even the high-dose of sildenafil was non-toxic for histological and ultrastructural integrity of the tissue.

As a result, this study is the first in terms of histopathological, anti-inflammatory and ultrastructural effects of sildenafil on the rectum of an ARP rat model. Yet, many clinical studies, especially biochemical and molecular studies are needed to support these effects of sildenafil. Our study may be a pilot research in this respect.

\section{References}

1. Hauer-Jensen $M$, Wang J, Boerma $M$, Fu Q, Denham JW. Radiation damage to the gastrointestinal tract: mechanisms, diagnosis, and management. Curr Opin Support Palliat Care. 2007 Apr;1(1):23-9. dol: 10.1097/SPC.0b013e3281108014.

2. Baughan CA, Canney PA, Buchanan RB, Pickering RM. A randomized trial to assess the efficacy of 5-aminosalicylic acid for the prevention of radiation enteritis. Clin Oncol (R Coll Radiol). 1993;5:19-24. doı: 10.1016/ S0936-6555(05)80689-2.

3. Swaroop VSGC, Gostout CJ. Endoscopic treatment of chronic radiation proctopathy. J Clin Gastroenterol. 1998;27(1):36-40 PMID: 9706767.

4. Hayne D, Vaizey CJ, Boulos PB. Anorectal injury following pelvic radiotherapy. Br J Surg. 2001;88(8):1037-48. doı: 10.1046/j.00071323.2001.01809.x.

5. Okunieff $P$, Cornelison $T$, Mester $M$, Liu W, Ding I, Chen $\mathrm{Y}$, Zhang $\mathrm{H}$, Williams JP, Finkelstein J. Mechanism and modification of gastrointestinal soft tissue response to radiation: role of growth factors. Int J Radiat Oncol Biol Phys. 2005;62(1):273-8. dol: 10.1016/j.ijrobp.2005.01.034.

6. Shadad AK, Sullivan FJ, Martin JD, Egan LJ. Gastrointestinal radiation injury: symptoms, risk factors and mechanisms. World J Gastroenterol. 2013;19(2):185-98. dol: 10.3748/wjg.v19.i2.185.

7. Trzcinski R, Dziki A, Brys M, MoszynskaZielinska M, Chalubinska-Fendler J, Mik M, Kujawski R, Dziki L. Expression of vascular endothelial growth factor and its correlation with clinical symptoms and endoscopic findings in patients with chronic radiation proctitis. Colorectal Dis. 2018 Apr;20(4):321330. doi: 10.1111/codi.13902.

8. Corbin JD. Mechanisms of action of PDE5 inhibition in erectile dysfunction. Int J Impot Res. 2004;16:S4-S7. doi: 10.1038/ sj.ijir.3901205.

9. Galie N, Ghofrani HA, Torbicki A, Barst RJ, Rubin LJ, Badesch D, Fleming T, Parpia T, Burgess $G$, Branzi A, Grimminger F, Kurzyna $M$, Simonneau $G$. Sildenafil citrate therapy for pulmonary arterial hypertension. N Engl J Med. 2005;353:2148-57. doi: 10.1056/ NEJMoa050010.

10.Gammella E, Leuenberger C, Gassmann M, OstergaardL.Evidence of synergistic/additive effects of sildenafil and erythropoietin in enhancing survival and migration of hypoxic endothelial cells. Am J Physiol Lung Cell Mol Physiol. 2013 Feb 15;304(4):L230-9. doi: 10.1152/ajplung.00112.2012.

11.Choi DE, Jeong JY, Lim BJ, Chung S, Chang YK, Lee SJ, Na KR, Kim SY, Shin YT, Lee KW. Pretreatment of sildenafil attenuates ischemia- reperfusion renal injury in rats. Am J Physiol Renal Physiol. 2009;297:F36270. doi: 10.1152/ajprenal.90609.2008.

12.Gori T, Sicuro S, Dragoni S, Donati G, Forconi S, Parker JD. Sildenafil prevents endothelial dysfunction induced by ischemia and reperfusion via opening of adenosine triphosphate-sensitive potassium channels: a human in vivo study. Circulation. 2005;111:742-6. doi: 10.1161/01. CIR.0000155252.23933.2D.

13. Katz SD, Balidemaj K, Homma S, Wu $\mathrm{H}$, Wang J, Maybaum S. Acute type 5 phosphodiesterase inhibition with sildenafil enhances flow-mediated vasodilation in patients with chronic heart failure. J Am Coll Cardiol. 2000;36:845-51. doi: 10.1016/ S0735-1097(00)00790-7.

14. Halcox JP, Nour KR, Zalos G, Mincemoyer RA, Waclawiw M, Rivera CE, Willie G, Ellahham $S$, Quyyumi AA. The effect of sildenafil on 
human vascular function, platelet activation, and myocardial ischemia. J Am Coll Cardiol. 2002;40:1232-40. doi: 10.1016/S07351097(02)02139-3.

15.Kukreja RC, Salloum FN, Das A, Koka S, Ockaili RA, Xi L. Emerging new uses of phosphodiesterase- 5 inhibitors in cardiovascular diseases. Exp Clin Cardiol. 2011;16:e30-5. PMID: 22131856.

16.Sezer A, Usta U, Kocak Z, Yagci MA. The effect of a flavonoid fractions diosmin + hesperidin on radiation-induced acute proctitis in a rat model. J Cancer Res Ther. 2011 Apr-Jun;7(2):152-6. doi: 10.4103/09731482.82927.

17.Ertürküner SP, Yaprak Saraç E, Göçmez SS, Ekmekçi H, Öztürk ZB, Seçkin I, Sever Ö, Keskinbora K. Anti-inflammatory and ultrastructural effects of Turkish propolis in a rat model of endotoxin-induced uveitis. Folia Histochem Cytobiol. 2016;54(1):49-57. doi: 10.5603/FHC.a2016.0004.

18.Seckin I, Uzunalan M, Pekpak M, Kokturk S, Sonmez H, Oztürk Z, Demirci S, Yaprak E. Experimentally induced puromycine aminonucleoside nephrosis (PAN) in rats: evaluation of angiogenic protein plateletderived endothelial cell growth factor (PDECGF) expression in glomeruli. J Biomed Sci. 2012 Feb 16;19:24. doi: 10.1186/14230127-19-24.

19.Do NL, Nagle D, Poylin VY. Radiation proctitis: current strategies in management. Gastroenterol Res Pract. 2011;2011:917941. doi: 10.1155/2011/917941.

20.Gültekin FA, Bakkal BH, Sümer D, Köktürk F, Bektaş S. Effects of ozonated olive oil on acute radiation proctitis in rats. Balkan Med J. 2013 Dec;30(4):369-74. doi: 10.5152/ balkanmedj.2013.9158.

21.Doi H, Kamikonya N, Takada Y, Fujiwara M, Tsuboi K, Inoue H, Tanooka M, Nakamura T, Shikata T, Tsujimura T, Hirota S. Efficacy of polaprezinc for acute radiation proctitis in a rat model. Int J Radiat Oncol Biol Phys. 2011 Jul 1;80(3):877-84. doi: 10.1016/j. ijrobp.2011.01.009.

22.Kronfol Z, Remick DG. Cytokines and the brain: implications for clinical psychiatry. Am J Psychiatry. 2000 May;157(5):683-94. doi: 10.1176/appi.ajp.157.5.683.

23.Duff GW. Cytokines and anti-cytokines. $\mathrm{Br}$ J Rheumatol. 1993 Mar;32 Suppl 1:15-20.
PMID: 8448631.

24.Duffy AM, Bouchier-Hayes DJ, Harmey $\mathrm{JH}$. Vascular endothelial growth factor (VEGF) and its role in non-endothelial cells: autocrine signalling by VEGF. Madame Curie Bioscience Database: Landes Bioscience; 2000.

25.West CM, Barnett GC. Genetics and genomics of radiotherapy toxicity: towards prediction. Genome Med. 2011;3:268-82. doi: $10.1186 / g m 268$.

26.Gibson A. Phosphodiesterase 5 inhibitors and nitrergic transmission-from zaprinast to sildenafil. Eur J Pharmacol. 2001;411(12):1-10. PMID: 11137852.

27.Santos CL, Souza MHLP, Gomes AS, Lemos $H P$, Santos AA, Cunha FQ, Wallace JL. Sildenafil prevents indomethacin-induced gastropathy in rats: role of leukocyte adherence and gastric blood flow. $\mathrm{Br} J$ Pharmacol. 2005;146:481-6. doi: 10.1038/ sj.bjp.0706361.

28.Iseri SO, Ersoy Y, Ercan F, Yuksel M, Atukeren P, Gumustas K, Alican I. The effect of sildenafil, a phosphodiesterase-5 inhibitor, on acetic acid-induced colonic inflammation in the rat. J Gastroenterol Hepatol. 2009;24(6):1440-8. doi: 10.1111/j.14401746.2009.05797.x.

29.Yildirim A, Ersoy Y, Ercan F, Atukeren P, Gumustas K, Uslu U, Alican I. Phosphodiesterase-5 inhibition by sildenafil citrate in a rat model of bleomycininduced lung fibrosis. Pulm Pharmacol Ther. 2010;23:215-21. doi: 10.1016/j. pupt.2009.11.002.

30.Wang HD, Yamaya M, Okinaga S, LJia YX, Kamanaka M, Takahashi H, Guo LY, Ohrui T, Sasaki H. Bilirubin ameliorates bleomycininduced pulmonary fibrosis in rats. Am J Respir Crit Care Med. 2002;165:406-11. doi: 10.1164/ajrccm.165.3.2003149.

31.Jeong $\mathrm{K}-\mathrm{H}$, Lee $\mathrm{T}-\mathrm{W}$, Ihm $\mathrm{C}-\mathrm{G}$, Lee $\mathrm{S}-\mathrm{H}$, Moon J-Y, Lim S-J. Effects of sildenafil on oxidative and inflammatory injuries of the kidney in streptozocin-induced diabetic rats. Am J Nephrol. 2009;29:274-82. doi: 10.1159/000158635.

32. Nakamura $S$, Ohtani $H$, Watanabe $Y$, Fukushima K,Matsumoto $T$, Kitano $A$, Kobayashi K, Nagura H. In situ expression of the cell adhesion molecules in inflammatory 
bowel disease. Evidence of immunologic activation of vascular endothelial cells. Lab Invest. 1993;69:77-85. PMID: 7687311.

33.Ito $Y$, Kinoshita $M$, Yamamoto $T$, Sato $T$, Obara T, Saitoh D, Seki SY. A combination of pre- and post-exposure ascorbic acid rescues mice from radiation-induced lethal gastrointestinal damage. Int J Mol Sci. 2013 Sep 27;14(10):19618-3. doi: 10.3390/ ijms141019618.

34. Haboubi NY, Schofield PF, Rowland PL. The light and electron microscopic features of early and late phase radiation-induced proctitis. Am J Gastroenterol. 1988 Oct;83(10):1140-4. PMID: 3421224.

\section{Acknowledgement}

To Prof. Dr. Seyhun Solakoglu and his team for performing transmission electron microscopical studies in İstanbul Faculty of Medicine, Department of Histology and Embryology.

\section{Correspondence:}

Erkan Yavuz

University of Health Science Bagcilar Training and Research Hospital

Department of General Surgery

Merkez Mh., Dr. Sadık Ahmet Caddesi, 34100

Bagcilar İstanbul

81drerkanyavuz@gmail.com

drerkanyavuz81@mynet.com

Received: Dec 16, 2017

Review: Feb 18, 2018

Accepted: Mar 20, 2018
Conflict of interest: none

Financial source: Istanbul Bagcilar Training and Research Hospital Educational Planning (Project no 2015-17) 